\title{
REFLEXÃO SOBRE O PAPEL DO SETOR IMOBILIÁRIO NA ACUMULAÇÃO URBANA
}

\section{Reflection on the real estate role in the urban accumulation}

\author{
Adauto Gomes Barbosa \\ Instituto Federal de Pernambuco, Recife, Pernambuco, Brasil. \\ adautogb@gmail.com \\ Edvânia Tôrres Aguiar Gomes \\ Universidade Federal de Pernambuco, Recife, Pernambuco, Brasil. \\ torres@ufpe.br
}

Artigo recebido em 08/04/2016 e aceito para publicação em 07/12/2016

RESUMO: Faz-se uma reflexão teórica sobre o papel do setor imobiliário no processo de acumulação urbana, tendo por base, o contexto empírico formado pelo Complexo Imobiliário Reserva do Paiva, situado no litoral sul da região metropolitana do Recife. Dentre os distintos papéis e agentes envolvidos, enfatiza-se o papel dos proprietários fundiários, dos incorporadores imobiliários e do Estado, sendo este último uma instância que age no jogo econômico e político sempre com o propósito de favorecer frações do capital que compõem o bloco no poder. Nesse contexto, traz à tona certos condicionantes do mercado e do Estado que interferem na produção imobiliária, ao mesmo tempo em que procura mostrar a forte relação entre a produção da cidade e as estratégias dos agentes capitalistas imobiliários. Desse modo, a reflexão procura desvendar como o espaço constitui um instrumental para as ações do Estado e, ao mesmo tempo, é permeado pelas contradições que marcam a atuação deste sob o capitalismo.

Palavras-chave: Acumulação urbana; Agentes produtores do espaço; Reserva do Paiva; Setor imobiliário.

ABSTRACT: This paper is a theoretical reflection about the role of the real estate sector in the process of urban accumulation, considering the empirical context of the real estate complexes of Reserva do Paiva, located to the South of the Metropolitan Region of Recife in the state of Pernambuco, Brazil. Among the many roles and agents involved, the role of land owners, Real Estate developers and the Government is emphasized. It is seen that the latter acts in this business favoring the capital of the powerful ones. In this framework, the paper brings some conditions of the market and the government that interfere in the Real Estate development and present a strong relation between the city development and the capitalist strategies of the Real Estate agents. In this way, the reflection in this paper aims at unveiling how the space is an instrument for governmental actions as it is also influenced by the contradictions between the Government and the capitalism.

Keywords: Urban Accumulation; Agents of space production; Reserva do Paiva; Real Estate. 


\section{INTRODUÇÃO}

No espaço urbano, o processo de produção imobiliária, intensificado e diversificado na contemporaneidade, compreende diferentes estratégias articuladas e diversos agentes com vista à fomentação de ofertas no espaço, especialmente nos espaços urbanos contingenciados em extensão e/ou infraestrutura, por exemplo. Invariavelmente, imóveis são produzidos e novos espaços de reprodução do capital são incorporados, sobretudo, nos empreendimentos imobiliários de grande monta, agentes econômicos operam sistemicamente com vista à produção do espaço urbano. Desse modo, exercem forte influência no mercado, no valor dos imóveis e nas decisões sobre os investimentos públicos e privados (FIX, 2007). Trata-se de agentes produtores do espaço urbano, designação largamente empregada por Corrêa (1995; 2011), também denominados city builders (LOGAN; MOLOTCH, 2007) ou, literalmente, construtores de cidades.

$\mathrm{Na}$ esfera vivida do capitalismo voraz e tão veloz, nem sempre o papel de cada agente fica claramente definido, em especial considerando o modelo neoliberal que norteia o planejamento e a gestão dos espaços urbanos, de expansão urbana ou potenciais. Nesse sentido e só para efeito de um desenho didático, ainda que se dê ênfase aqui ao papel dos produtores fundiários, dos incorporadores e do Estado, toma-se por base neste artigo a seguinte tipologia: agentes do setor imobiliário e financeiro; agentes institucionais da esfera governamental e não governamental; empresas de locação, comercialização e administração predial; incorporadoras; empresas que atuam no ramo de gestão da obra; empresas construtoras; consultorias de marketing, meio ambiente e de responsabilidade social; e empresas de elaboração dos projetos de engenharia e de projetos arquitetônicos, dentre outras. Assim, é frequente, em especial nas grandes intervenções imobiliárias, que um mesmo agente desempenhe de forma simultânea mais de uma dessas atividades, havendo ainda uma complexa rede de colaboração entre as empresas. A figura da Parceria Público-Privada (PPP) nas Operações Urbanas, prevista no Estatuto da Cidade (Lei n. ${ }^{\circ} 10.257$ de 10 de julho de 2001), ilustra bem, na teoria e na prática, o caráter imbricado dessa teia de agentes.
Logan e Molotch (2007) afirmam que, de várias maneiras, os city builders buscam influir no funcionamento do mercado. Assim, com um aguçado senso de oportunidade em converter as distintas localizações na cidade em possibilidades reais de lucros, eles lançam mão de inúmeras estratégias com tal finalidade. Dessa forma, sua atuação concorre para a estratificação social do espaço urbano, visto que certos espaços tornam-se alvo potencial ou real de investimentos imobiliários ao passo que outros tendem a manter o quadro de carências. Nessa visão, é importante enxergar que a ação dos agentes capitalistas produtores do espaço urbano ocorre segundo as oportunidades reais e/ou potenciais oferecidas pelo mercado. Na busca de atrair investimentos públicos e privados, as cidades funcionariam como "máquinas de crescimento" (LOGAN; MOLOTCH, 2007) visando alimentar seu crescimento econômico e, nesse movimento contraditório, promover a reprodução/ acumulação do capital.

O crescimento da cidade, a expansão ou dilatação dos espaços urbanos, com a incorporação de novas parcelas, já não são suficientes per si. Há demandas de ações mais velozes, mais criativas, que habilitem maior fluxo de caixa para os principais agentes imobiliários. Tanto mais rápido e mais criativamente haja a produção e reprodução dos produtos imobiliários, mais palpitante torna-se a demanda pelo capital que financeiriza a aquisição dessas mercadorias. Para os agentes produtores do espaço urbano, quanto mais a cidade cresce, maiores também são as possibilidades efetivas de tais agentes auferirem ganhos com o crescimento. Nesse processo, a mídia veicula a publicidade para comercialização competentemente acercando-se dos símbolos e signos que imprimem a ideia de progresso, desenvolvimento, lazer, privacidade, e ou qualquer apelo que guarde a conveniência contextual. Essas publicidades constituem imperativos sistêmicos do mercado e da permissividade normativo-administrativa, conforme já mencionado por Habermas na teoria da ação comunicativa, acabando por colonizar o mundo da vida urbana de maneira inexorável (HABERMAS, 1984).

Em face dessas aproximações teórico-metodológicas, este artigo contempla reflexões teóricas sobre o processo de produção e reprodução do espaço em 
uma metrópole brasileira, tendo como objeto dialógico o referencial empírico constituído pelo Complexo Imobiliário Reserva do Paiva, situado no litoral sul da região metropolitana do Recife. A condição relacional indissociável do valor de uso e de troca no processo de acumulação urbana é pontuada como elemento introdutório das ideias aqui contidas.

\section{VALOR DE USO E VALOR DE TROCA E SUA INTER-RELAÇÃO NO SETOR IMOBILIÁRIO}

Todo valor de troca contém em si alguma utilidade imanente que lhe permite uma existência relacional com o valor de uso (HARVEY, 1980). Desse modo, a existência do valor de troca vincula-se à sua possibilidade efetiva de uso e, em última instância, volta-se para o processo de consumo, portanto, para o uso. Segundo Marx (2000, p. 70): “Se, por um lado, a mercadoria só pode vir a ser valor de uso efetivando-se como valor de troca, por outro lado, ela só pode efetivar-se como valor de troca confirmando-se como valor de uso em sua alienação." Está clara a indissociabilidade dessas duas dimensões de valor segundo a ótica marxista, que é a assumida aqui.

A afirmativa de Mészáros (2002, p. 660) ratifica de forma bem atual e vívida a mercantilização do espaço e de todo o conjunto multiescalar e processual nele contido e/ou a conter no movimento de produção e reprodução do capital: "O capital não trata meramente como separados valor de uso (que corresponde diretamente à necessidade) e valor de troca, mas o faz de modo a subordinar radicalmente o primeiro ao último." Isso quer dizer que, no mundo regido pela lógica da reprodução/acumulação do capital, há uma submissão do uso à troca. Em razão disso, "o capital define como 'útil' e 'utilidade' em termos de vendabilidade: um imperativo que pode ser realizado sob a hegemonia e no domínio do próprio valor de troca" (MÉSZÁROS, 2002, p. 661, grifos do autor). Assim, é sua intercambialidade no mercado que faz da mercadoria um elemento estratégico para o capital, e o uso, em certo sentido, torna-se um fator que possibilita a realização da troca.

O setor imobiliário é exemplar e definidor na realização direta ou indireta de todas as atividades que se processam no espaço urbano, e a cidade se configura como um grande sistema de objetos imobiliários e de ações a ele vinculadas. Nesse quadro de referência, o capital precisa, permanentemente, produzir (e reproduzir) a cidade por meio da criação de espaços ou a reconfiguração dos já existentes de forma a assegurar sua circulação. O que aparentemente se apresenta como impeditivo para maior circulação do capital em vista da longa durabilidade do produto imobiliário, bem como da sua fixidez ao solo, seu custo elevado e a baixa composição orgânica do capital investido, como afirma Lefebvre (2007), acaba por ser um fator assimilado e metamorfoseado dinamicamente pelos agentes imobiliários.

Justifica-se, assim, o conjunto de iniciativas que se revezam a cada período da história como grande novidade. Nesse sentido, foram concebidos projetos de revitalização dos centros históricos, especialmente no Brasil nas décadas de 1970 e 1980 . Nessa mesma direção, surgiram conjuntos habitacionais periféricos distantes o suficiente dos centros urbanos para que permitissem o desfrute dos espaços intersticiais pelo capital atuante no setor imobiliário. Enfim, pode ser recuperada aqui uma série de "ondas" do planejamento, gestão e intervenção urbana que se vinculam àquelas peculiaridades das edificações dos bens imóveis.

Ademais, os bens imóveis abrangem diversos elementos espaciais como as edificações sobre a terra para fins residenciais, comerciais, industriais e a melhoria de infraestrutura, portos e estradas, tendo ainda um mercado regido por leis bem específicas. Portanto, “o bem imóvel sob o capitalismo é um produto social que não pode ser separado das forças ou instituições econômicas, políticas e culturais, como, por exemplo, as do capital financeiro, que administram e regulam os usos do espaço" (GOTTDIENER, 2010, p. 179). Por conta disso, há uma forte imbricação entre o setor imobiliário e o capital financeiro, ambos mediados pelo Estado. Aliás, este último agente, embora às vezes atue como construtor (e por vezes como proprietário fundiário), seu papel por excelência é o de regular o uso do solo e fiscalizar a produção imobiliária, com todas as implicações políticas daí advindas.

Ao fazer análise teórica sobre esse tema, embora volvido em especial para a produção da habitação, Topalov (1979) destaca outras particularidades relativas ao solo urbano e ao setor imobiliário. Des- 
tarte, a moradia irremediavelmente ligada ao terreno implica que, a cada nova habitação, é necessário um novo terreno, cujo tempo de consumo é muito longo. Por sua vez, a propriedade da terra, em certos casos, coloca-se como um óbice à produção imobiliária, mas o custo unitário dessa mercadoria é muito alto e isso se traduz em uma demanda solvável bastante reduzida.

$\mathrm{O}$ efeito disso tudo é que tais peculiaridades implicam um tempo muito longo de giro do capital, tanto durante a produção quanto na sua circulação como capital-dinheiro. Desse modo: "Quanto mais longo o tempo de giro de determinado capital, menor é o rendimento anual da mais-valia." (HARVEY, 2005, p. 50). O sistema imobiliário trata de superar essa condição, promovendo reserva de áreas, sejam aquelas construídas e muitas vezes obsoletas, ou aqueles terrenos na zona de expansão urbana, estrategicamente situados e beneficiados pela proximidade com certos empreendimentos que lhe agregarão valor. Aí reside a capacidade de permanente expansão sociometabólica do capital (MÉSZÁROS, 2002). Isso significa que a condição relacional do valor de uso e do valor de troca no setor imobiliário representa um jogo sutil e móvel, no qual determinados agentes conduzem e determinam a expansão e transformação do espaço urbano, de acordo com os interesses e conveniências conjunturais no processo de acumulação/reprodução do capital.

Em muitos casos, os vetores de viabilização da produção do espaço como condição para a acumulação/reprodução do capital se materializam, em certos contextos, como uma antecipação espacial, e aparentemente não tem muito sentido a inversão de recursos na implantação de uma infraestrutura que a princípio parece não ter um propósito consistente, ao menos à primeira vista. Contudo, tal como ressaltam Gomes e Albuquerque (2013), as inversões podem ser parte de um projeto maior que altera sobremaneira a estruturação do espaço da cidade para atender aos ditames dos agentes hegemônicos que produzem o espaço urbano. Esse fenômeno é claramente visibilizado no caso da implantação da Via Mangue, via expressa apresentada como suposta solução para o problema de mobilidade urbana na zona sul do Recife, mas que, de forma estratégica, criou um eixo de valorização e de reprodução do capital no espaço da cidade. Nesse contexto, a reprodução do espaço dessa metrópole se viabiliza pela alteração drástica de algumas áreas de vulnerabilidade social e ambiental, as quais se tornam espaços privilegiados de instalação de shopping center, condomínios empresariais e residenciais de alto padrão de habitabilidade, tal como na área dos bairros do Pina e de Boa Viagem, diretamente valorizadas pela implantação desse complexo viário.

Assim, os agentes produtores da cidade, quer os proprietários fundiários, os incorporadores, os construtores, quer o próprio Estado (só para ficar nos exemplos mais notáveis)l, negociam seus interesses na realização de suas estratégias de obtenção dos lucros e na realização da mais valia.

Por seu turno, embora não seja condição sine qua non, o sistema imobiliário tem mais liquidez quando operado sobre terrenos livres de construção, bem como em novas zonas de expansão urbana, e até em áreas de reserva. Na escassez desse tipo de mercadoria, seja pela indisponibilidade de terreno, seja pelo alto valor do que representaria o investimento na oportunidade, a apropriação de terrenos com construções não impõe limites ao capital. Toda a sorte de mecanismo é utilizada para chegar à realização de novas intervenções imobiliárias, inclusive as estratégias de transformação em áreas de risco social, vulnerabilidade e/ou práticas de manipulação midiática com auxílio dos agentes estatais e privados da sociedade. Assim, são demolidas construções que dão lugar a novas edificações. Configura-se um processo permanente de construção, destruição e reconstrução do ambiente construído; nem que seja do ponto de vista simbólico, a obsolescência do espaço construído torna-se um imperativo para o capital desencadear um novo ciclo de destruição-construção. No período atual, há mesmo um recorrente processo de destruição criativa (HARVEY, 1992).

À luz da lógica do mercado, o que justifica pagar um alto preço por um imóvel na Reserva do Paiva é tanto a possibilidade de uso quanto o fato de constituir uma mercadoria com grande valor agregado, que permite auferir ganhos com sua revenda ou aluguel. Aliás, ao identificarem o perfil de quem compra imóveis nesse empreendimento, os corretores logo indicam que esses bens tanto têm grande aceitação como valor de uso (para fins de moradia e do ponto 
próprio de comércio) quanto valor de troca (para fins de revenda), com vista a se obter retorno financeiro. Em ambos os contextos, tais perspectivas do valor imbricam-se na mesma mercadoria.

$\mathrm{Na}$ perspectiva relacional, portanto, valor de uso e valor de troca são duas faces da mesma moeda, haja vista que, no ato da troca, essas duas dimensões estão imbricadas e carregam consigo uma contradição essencial, qual seja, o fato de a possibilidade do uso ser um meio para viabilizar a troca. Nesse processo:

O impulso motivador e o objetivo determinante de cada parte presente na troca de duas mercadorias são a necessidade de possuir o valor de uso da mercadoria da outra parte envolvida. Ao mesmo tempo, a própria mercadoria, e com ela a necessidade alheia, é somente um meio para atingir um fim. $O$ objetivo de umé, por sua vez, o meio do outro para chegar ao próprio fim por meio da troca. Assim, num único ato de troca defrontam-se duas vezes duas perspectivas opostas. Ambas assumem tanto a perspectiva do valor de troca, quanto uma determinada perspectiva do valor de uso. A cada perspectiva do valor de uso opõe-se uma perspectiva do valor de troca, pela qual ela é possivelmente enganada. (HAUG, 1997, p. 24-25).

$\mathrm{Na}$ sociedade capitalista, o valor de uso subordina-se ao valor de troca, pois as mercadorias são produzidas, primordialmente, para a extração de mais-valia, e não exatamente para a satisfação das necessidades sociais. Uma demonstração clara disso é o fato de que muitos produtos são produzidos sob o signo da obsolescência programada (HAUG, 1997), isto é, não são feitos para durar muito, para que os consumidores precisem em tempo relativamente curto voltar ao mercado para adquirir novas mercadorias e dessa maneira acelera-se o giro e a consequente reprodução do capital.

Não obstante a longa durabilidade dos bens imóveis, a obsolescência programada é parte intrínseca desse processo e relaciona-se diretamente com a lucratividade das empresas. À luz da estética da mercadoria (HAUG, 1997), a curta durabilidade de um bem nem sempre se relaciona com a sua depreciação para o uso, mas com a rápida substituição por outros modelos e designs lançados no mercado. Malgrado a mercadoria habitação padeça do mal de "durar muito", o capital encontra opções para esse "problema" anunciando novos conceitos de produtos imobiliários e impondo novas necessidades sociais. No contexto empírico investigado, prevalece certa "lógica de morte", com base na qual se confrontam as ditas positividades da Reserva do Paiva com negatividades de Boa Viagem, embutindo o propósito de evocar as qualidades pretensamente superiores daquele complexo imobiliário em relação a esse bairro nobre do Recife.

Segundo Mészáros (2002), é o processo de sociometabolização do capital que permeia tudo isso. O sistema do capital constitui um modo de controle sociometabólico incontrolavelmente voltado para sua expansão contínua no tempo e no espaço. É em nome dessa expansão que tudo está subordinado ao capital, ficando até mesmo as necessidades humanas primordiais em segundo ou terceiro planos. É em nome dessa necessidade estrutural de expansão contínua e acelerada do capital que tudo o mais se torna secundário diante da acumulação e reprodução capitalista. Desse modo emergem as contradições do espaço-mercadoria na cidade capitalista, com a vitória do valor de troca sobre o valor de uso.

Paralelamente a isso, a criação de frentes da expansão urbana liga-se amplamente à acumulação do capital. Nesse sentido, Harvey (2005) fala em ajuste espacial para afirmar que o capital cria espaços de crescimento, fazendo surgir novas demandas por infraestruturas, residências, equipamentos urbanos, edifícios corporativos, etc., e o setor imobiliário desempenha papel crucial nesse processo. $\mathrm{O}$ ajuste espacial põe-se como uma necessidade do capital que, em tempos de crise, se desloca para o imobiliário, produzindo e reproduzindo o espaço como parte da lógica da acumulação.

Conforme as palavras de Harvey (2005, p. 193): "A acumulação do capital sempre foi uma ocorrência profundamente geográfica. Sem as possibilidades inerentes da expansão geográfica, da reorganização espacial e do desenvolvimento geográfico desigual, o capitalismo, há muito tempo, teria deixado de funcionar." Em resumo, trata-se da mobilização 
de espaço para assegurar a reprodução e acumulação de capital por meio do setor imobiliário. Tal é o caso típico do complexo Reserva do Paiva, assim como de outros igualmente importantes megaprojetos imobiliários nas médias e grandes cidades brasileiras e no seu entorno.

O fato é que há uma crescente inserção do setor imobiliário no circuito da produção - consumo de forma geral. Malgrado seja ele normalmente um setor compensatório, "ele pode até tornar-se um setor principal se o circuito normal 'produção - consumo' arrefecer, se houver recessão" (LEFEBVRE, 2008, p. 71). Há, dessa maneira, um quadro de interferências mútuas entre o imobiliário e outros segmentos econômicos. Daí que esse setor funciona como um amortizador de crises cíclicas do capitalismo e, ao mesmo tempo, um imobilizador do capital nele investido. Significa dizer que, geralmente, em tempos de crise, investir em imóveis constitui uma opção segura.

Sendo assim, a especulação é um elemento do mercado livre de terra, o qual constitui uma combinação dos diversos agentes capitalistas imobiliários, envolvendo proprietários fundiários, corretores, bancos, investidores, especuladores, empresas de construção e agências de financiamento. Gottdiener (1996, p. 22) afirma que esse complexo de agentes com suas estratégias "forma um segundo circuito do capital e, em combinação com o primeiro circuito de acumulação localizado na indústria e nos serviços, cumpre papel na base da crise do capitalismo". Dessa forma, os capitais de outros segmentos econômicos encontram no imobiliário uma espécie de refúgio, por ocasião de crises econômicas, contudo, também nas fases de expansão, é um dos segmentos da economia que mais absorvem investimentos e estimulam outros que se relacionam com ele, fornecendo materiais, prestando consultorias ou dele recebendo produtos prontos para o mercado.

Esse é um papel muito estratégico desempenhado pelo setor imobiliário para a acumulação urbana, não obstante durante muito tempo tenha sido considerado pouco importante para o capitalismo. "Ora, a situação desse 'ramo' mudou completamente, e não apenas nos grandes países industriais." (LEFEBVRE, 2008, p. 118). O solo urbano torna-se estratégico como mercadoria. Logo, o que outrora era considerado "imobilizado" tornou-se "mobilizado" por meio de construções e especulações e forte inserção do capital financeiro e suas inúmeras operações e os distintos agentes que se inserem no processo de acumulação urbana.

\section{O PAPEL DOS PROPRIETÁRIOS FUNDIÁRIOS E DO CAPITAL DE INCORPORAÇÃO}

Os proprietários fundiários se põem como agentes estratégicos na definição das novas direções assumidas pelo crescimento da cidade. Isso implica dizer que não seria razoável discutir as estratégias imobiliárias sem considerar o papel proeminente desses agentes. Dependendo de cada situação, os proprietários fundiários não constituem pessoas físicas, mas, sim, jurídicas e de ramos de atuação bastante distintos, como fundos de pensão, fundos de investimentos imobiliários ou ainda as próprias empresas especializadas no segmento build-to-suit.

Segundo Harvey $(2005 ; 2011)$, na produção do espaço urbano, os proprietários fundiários configuram um segmento capitalista que tem grande interesse nas transformações que resultam na produção do espaço edificado da cidade. Eles estão plenamente integrados ao capitalismo e mais:

é vital vê-lo como um poder ativo e não passivo, pois é justamente por meio da realização de novas geografias que os proprietários (em aliança com desenvolvedores, interesses da construção e, claro, financiadores onipresentes) avançam a sua posição de classe, além de trazer soluções-chave para o problema da absorção do excedente de capital. (HARVEY, 2011, p. 149).

Desse modo, os proprietários procuram decidir sobre o momento mais propício para vender sua terra, convertendo-a em capital-dinheiro. Em certos casos, não se limitam a vender a base fundiária, já que podem fazer parceria com grande incorporadora de modo a participar estruturalmente de todo o processo de desenvolvimento do empreendimento.

Os agentes em contexto adquirem muita experiência e também conhecem o movimento do mercado imobiliário de maneira que procuram participar dele 
como tomadores de decisão, e não meros "fornecedores de terras" para outros investidores. Em situação privilegiada, o capital fundiário usufrui plenamente da condição de mercadoria do solo urbano, explorando tal virtualidade à medida que emergem novas ondas de investimento, sob o impulso do Estado ou por meio das próprias estratégias, pautadas em coalizões entre as próprias corporações privadas e em outros casos, como as parcerias público-privadas (PPPs).

Em certos casos, terras rurais são transformadas em urbanas graças às alterações no plano urbanístico municipal. Leitão (1999) ressalta que, no processo de expansão urbana, o valor do solo é determinado pelo uso ao qual se destina e pela renda do estrato social que poderá ocupá-lo. Nesse aspecto, uma área localizada no entorno da cidade ou outra que passou a contar com determinada infraestrutura urbana pode tornar-se alvo dos estratos de alto poder aquisitivo e, com isso, possibilitar elevada extração de renda pelo proprietário. Nesse caso, os preços podem variar no mercado conforme a clientela-alvo que vai fixar-se lá.

Ribeiro (1997) destaca três classes de fatores que interferem nos preços de terrenos voltados para o segmento residencial urbano: os fatores de microlocalização, os de macrolocalização e os gerais. No primeiro caso, são fatores que estão ligados diretamente às condições do meio ambiente, natural ou construído, com o qual o terreno está diretamente articulado. Dentre esses fatores, destacam-se: acessibilidade aos serviços locais, meio ambiente natural e vizinhança. Trata-se de elementos muito divulgados pela propaganda imobiliária, cujos primeiros beneficiários tendem a ser os proprietários fundiários.

No que se refere aos fatores de macrolocalização, exercem influência no conjunto de uma determinada área homogênea, a exemplo de um bairro, uma faixa ao longo de uma importante avenida, etc. São responsáveis pela formação diferenciada de preços do solo urbano em cada compartimento da cidade e, dessa forma, levam em conta aspectos como posição do bairro em relação ao centro, subcentros, campus universitário; ligação do bairro com o sistema de transporte; zoneamento urbano-ambiental, que pode favorecer determinado uso do solo e restringir outros. $\mathrm{Na}$ Reserva do Paiva, praticamente todos esses fatores se fazem presentes, graças, em grande medida, à atua- ção estrutural (LOGAN; MOLOTCH, 2007) dos seus agentes desenvolvedores, que incluem os proprietários e a incorporadora. Os agentes agem de forma estrutural quando têm forte capacidade de intervir para alterar as decisões do Estado e de outros agentes privados, criando condições que reestruturam o mercado em seu benefício. Como exemplo disso, a decisão por uma PPP que resultou na implantação da via pedagiada que dá acesso à Reserva do Paiva e encurta o percurso Recife-Complexo de Suape é expressão clara da atuação estrutural dos seus promotores imobiliários.

Os fatores gerais interferem na formação dos preços fundiários da cidade como um todo. Dentre tais fatores, podem ser citados o ritmo de crescimento, a conjuntura econômica e a estrutura da propriedade privada da terra (RIBEIRO, 1997). Como se nota, estão relacionados com fatores gerais cujas transformações não dependem unicamente da intervenção de um agente em particular. No que se refere ao complexo Reserva do Paiva, as demandas surgidas pela consolidação do Complexo Industrial-Portuário de Suape (CIPS), localizado relativamente próximo, estão entre seus fatores favoráveis. Não se deve esquecer ainda o aquecimento do mercado imobiliário, sobretudo no período de 2009-2014, marcado pelo forte incremento de investimentos estruturadores no CIPS e a expansão do crédito concedido pelos bancos públicos e privados. Sem dúvida, o ingresso de capital financeiro é determinante nesse processo.

As três classes de fatores supramencionadas têm impacto nas novas direções da expansão da cidade e são consideradas pelos proprietários fundiários nas suas estratégias de acumulação capitalista. Os fatores de micro e macrolocalização apresentam a limitação de se aplicarem muito mais à escala intraurbana e, em certa medida, não se aplicam aos estoques de terra rural que estão situados na franja periurbana, os quais são ainda estratégicos para os propósitos de acumulação capitalista pelos proprietários fundiários. Em áreas urbanas metropolitanas, tal como Recife, os megaprojetos imobiliários tendem a utilizar terras da franja periurbana pela maior disponibilidade de terrenos e pelos preços serem mais baixos, revelando-se, assim, uma urbanização pelas bordas.

Muitas vezes, enquanto aguardam que as condições de valorização de suas terras efetivamente 
se manifestem, sejam elas objetivas, sejam subjetivas, os proprietários tendem a fazer especulação imobiliária. Em última instância, é a lógica do capital, por meio de seu processo de reprodução/acumulação que comanda esse movimento de apropriação privada do espaço urbano em benefício de agentes individuais e em detrimento dos interesses coletivos.

No que toca ao capital de incorporação, ele compreende uma grande diversidade de empresas e agentes que participam do processo de gestão do capital dinheiro e promove a transformação do capital fixo constituído pela propriedade fundiária em capital circulante, o capital financeiro propriamente. Autores como Topalov (1979), Smolka (1987) e Corrêa (1995) afirmam que a incorporação é responsável pela gestão do capital-dinheiro ou de um capital imobiliário de circulação em sua fase de transformação em mercadoria, isto é, em imóvel.

A incorporação envolve diversas etapas: elaboração do projeto, que tratará da definição do tipo de empreendimento; informações básicas na prefeitura a respeito da situação jurídica do terreno a ser loteado; estudo da viabilidade econômica e financeira; composição de preços por unidade autônoma; cálculo do custo de construção; cálculo das receitas e despesas de incorporação; projeto de arquitetura; especificações básicas de material de construção a ser utilizado na obra; custo da construção e convenção do condomínio.

Outras atribuições do capital incorporador consistem em contratar consultoria para o levantamento das necessidades do mercado; negociar a permuta de futuras unidades autônomas com o proprietário do terreno e contratar agência de publicidade para a divulgação do empreendimento. Se ela mesma não o fizer, também pode contratar uma corretora de imóveis, fenômeno mais recorrente, para a comercialização das futuras unidades autônomas. A promoção capitalista imobiliária é, assim, um complexo sistema de atividades, com considerável divisão técnica e social do trabalho.

Por sua vez, de forma resumida, Azevedo (1982) levanta as atribuições do investidor incorporador, as quais compreendem distintas tarefas. Após selecionar o terreno urbano, ele concebe um determinado uso para a área e contrata os serviços de escritórios de planejamento, envolvendo o projeto de arquitetura e de engenharia e, por vezes, o urbanismo da área para o empreendimento. Em seguida, se necessário for, pro- cura obter financiamento para a construção, seguido da contratação de empresa construtora e execução da obra. Concluída a obra, cabe à corretora de imóveis a tarefa de comercializar as unidades construídas. Essa etapa quase sempre se inicia logo no lançamento do empreendimento, que geralmente ocorre pouco antes do início da obra, com sua divulgação na mídia. Ao vender unidades imobiliárias na planta, o investidor incorporador apropria-se antecipadamente de uma parte ou de todo o capital financeiro investido pelo comprador do imóvel, e isso contribui para financiar a conclusão da obra. Ao mesmo tempo, reduz a necessidade de recorrer a instituições para financiar o custo restante da construção.

No Brasil, as diversas operações que compõem a incorporação imobiliária só passaram a ter um marco legal em 1964, com a vigência da Lei Federal n. ${ }^{\circ}$ 4.591/64. Essa lei prescreve que a incorporação imobiliária é "a atividade exercida com o intuito de promover e realizar a construção, para alienação total ou parcial, de edificações ou conjunto de edificações compostas de unidades autônomas" (BRASIL, 1964, art. 28, parágrafo único). No projeto de loteamento de uma área, o investidor incorporador toma por base a Lei Federal n. ${ }^{\circ} 6.766 / 79$, que define loteamento, em seu artigo $2 .^{\circ}$, como "a subdivisão de gleba em lotes destinados a edificação, com abertura de novas vias de circulação, de logradouros públicos ou prolongamento, modificação ou ampliação das vias existentes" (BRASIL, 1979). A referida lei também trata de requisitos urbanísticos para loteamento, projeto de loteamento ou de desmembramento, registro do loteamento, dentre outros.

Figueiredo (2010) ressalta que, além da análise do projeto na Prefeitura, loteamentos que estão localizados em área metropolitana, como é o caso da Reserva do Paiva, precisam também ser aprovados no âmbito do órgão de planejamento metropolitano. A Lei n. ${ }^{\circ}$ 6.766/79 ainda prevê que, só depois de aprovado o loteamento e feito o registro imobiliário, o investidor incorporador pode pôr os lotes parcelados à venda quando for o caso, pois na Reserva do Paiva, por exemplo, são vendidas as edificações, nunca os lotes "nus".

Em todas as suas operações, o investidor incorporador atua no sentido de produzir valor no solo urbano mediante a alteração de seu uso e, nesse processo, segundo Almeida (apud SILVA, 1995, p. 8), a decisão de incorporação imobiliária abrange 
diversos fatores: 1) o valor da terra ligado ao status da localização; a acessibilidade física, eficiência e segurança dos meios de transportes; 3 ) o esgotamento do estoque de terrenos e as condições físicas do estoque de prédios de gerações de construção anteriores; 4) as amenidades em suas múltiplas variações, que obedecem a temporalidades diferentes.

No que concerne ao circuito de produção imobiliária, com a venda do imóvel, o investidor incorporador obterá o lucro e também o capital necessário para cobrir despesas diversas que envolvem tanto a construção, quanto outras operações, como a elaboração do projeto e a publicidade do empreendimento. O lucro do incorporador deve ser entendido como "valorização do capital próprio do incorporador, [que] deve ser no mínimo igual à remuneração obtida por um capital idêntico aplicado pelo período de imobilização a taxas médias do mercado" (AZEVEDO, 1982, p. 73-74). Em outras palavras, o lucro a ser obtido pelo incorporador deve corresponder, na pior das hipóteses, ao ganho que ele obteria se aplicasse seu recurso no mercado financeiro, durante o período em que o capital ficar imobilizado, com taxas médias de retorno. Obviamente, o capital oligomonopolista e, menos ainda, o monopolista, não trabalham com o cenário de lucro mínimo, pois o padrão construtivo de seus produtos imobiliários e sua clientela-alvo possibilitam-lhes altos retornos financeiros.

Os preços aplicados em relação aos imóveis residenciais dos megaprojetos, tal como a Reserva do Paiva, configuram-se como um preço de monopólio, o qual se relaciona com três fatores: a quantidade produzida, pois em geral não ocorre uma produção em série; a alta solvabilidade dos compradores, os quais têm forte capacidade de pagamento, pois correspondem aos estratos mais ricos, por isso são relativamente poucos no total da população (daí que não se pode produzir em série); e o alto grau de diferenciação real e/ou simbólica das moradias.

\section{AS INTERFACES DO ESTADO COMO CON- DENSAÇÃO DE FORÇAS}

Em sua interação com outros agentes produtores do urbano, o Estado exerce papel bastante peculiar, pois ora age como um grande agente construtor, ora como regulador, sendo este último, sua função por excelência, cabendo-lhe diligenciar a ação dos demais agentes. Desse modo, ele contribui de forma decisiva para produzir e reproduzir o espaço urbano, ainda que permeado pela ação imperativa do capital. Em praticamente todos os segmentos da economia, e não apenas no setor imobiliário, as várias frações do capital exercem pressão ao Estado, sobretudo com o intuito de obter vantagens econômicas.

Nesse jogo de forças o Estado não é uma instância à parte que se posicionaria de forma neutra e em nome dos interesses coletivos. Muito pelo contrário, ele assume uma postura de classe em favor dos interesses de determinadas frações do capital. Isso se coaduna com a visão de Poulantzas (1980), para quem o Estado funciona como condensação de forças, o que implica dizer que, em uma sociedade de classes, em que vigoram distintos interesses, os próprios interesses das frações de classe dominantes são conflituosos entre si e nisso o Estado não se posiciona como se estivesse acima do bem e do mal, ou seja, como se constituísse uma realidade à parte dos interesses particulares.

$\mathrm{Na}$ visão do autor em tela, o papel do Estado é justamente o de organizar os interesses do bloco no poder, expressão que designa as frações de classe que exercem maior domínio sobre outras em cada contexto político e econômico. Se o Estado não é um todo monolítico sem fissuras, igualmente, as classes dominantes não configuram um só grupo de interesses. Em certos momentos, a condensação de forças resulta da aliança de certas frações burguesas, porém, noutros momentos, tal condensação já representa novo arranjo envolvendo outras frações. Nesse sentido, a aliança de poder expressa sempre um equilíbrio instável dos compromissos das frações envolvidas, e é por meio desse jogo que se estabelece a hegemonia e a direção de umas frações de classe em detrimento de outras.

No contexto da produção do espaço urbano, isso fica bastante nítido visto que tal processo abarca diferentes agentes sociais e econômicos, com interesses diversos e por vezes contraditórios entre si. No caso da Reserva do Paiva, a coalizão dos proprietários fundiários com a incorporadora não é suficiente e exige a coalizão com distintos níveis do poder público, além de um jogo nem sempre explícito dos interesses de outros promotores imobiliários. Logo, defender 
suas ideias e valores e difundi-los é algo bastante estratégico para que nessa relação de forças o Estado lhe dê guarida.

Com muita frequência, agentes capitalistas exercem forte influência sobre a Academia e detêm forte inserção na mídia utilizada como ferramenta de disseminação das práticas sociais a serviço dos seus interesses. Não se pode perder de vista que a produção da cidade capitalista resulta em grande medida do papel das elites. Assim:

na medida em que dominam como classe $e$ determinam todo o âmbito de uma época histórica, é evidente que o façam em toda sua extensão e, consequentemente, entre outras coisas, dominem também como pensadores, como produtores de ideias; que regulem a produção e a distribuição das ideias de seu tempo e que suas ideias sejam, por isso mesmo, as ideias dominantes da época. (MARX; ENGELS, 1999, p. 72).

Logo, uma das formas de legitimação das ideologias dominantes ocorre justamente por meio do Estado, que as difunde como se este representasse o interesse comum e existisse de forma autônoma e desvencilhada dos interesses de classe. Não por acaso: "As noções de 'justiça', 'direito', 'liberdade' são apresentadas como se tivessem um significado independente de qualquer interesse de classe específico.”(HARVEY, 2005,p. 81, grifos do autor). Também na perspectiva desse autor, o Estado capitalista procura amparar e aplicar um sistema legal que envolve conceitos como propriedade, indivíduo, igualdade, liberdade e direito, de forma correspondente às relações de troca sob o capitalismo.

É importante considerar que as elites não atuam apenas de fora do aparelho estatal, elas atuam em dupla direção, de fora para dentro e de dentro para fora. Nesse sentido, "a natureza da intervenção do Estado garante a exploração multiforme e a igualdade na exploração mútua e recíproca, enquanto a lei garante a igualdade e, nesta, a manutenção da desigualdade" (CARLOS, 2011, p. 65). Longe de ser o defensor do bem comum, o Estado capitalista torna-se a expressão de interesses dos grupos hegemônicos, que, por isso mesmo, o controlam. Dessa forma:
In fact, and in practice, what state and political action institutes, and consolidates by every available means, is a balance of power between classes and fractions of classes, as between the spaces they occupy. What, then, is the state? According to the 'politicologists', it is a framework - that of a power which makes decisions in such a way as to ensure that the interests of certain minorities, of certain classes or fractions of classes, are imposed on societyso effectively imposed, in fact, that they become indistinguishable from the general interest. (LEFEBVRE, 2007, p. 280-281, grifo do autor).

O autor em tela ainda chama especial atenção para a relação entre o Estado e o espaço. Assim, para cada concepção de Estado, há um espaço instrumental de que ele faz uso para pôr em prática suas ações segundo os interesses das frações de classes dominantes. Ou seja: "Indeed each new form of state, each new form of political power, introduces its own particular way of partitioning space, its own particular administrative classification of discourses about space and about things and people in space." (LEFEBVRE, 2007, p. 281). Logo, da mesma forma que o Estado está a serviço dos interesses de algumas frações de classe, e não de toda a sociedade, o espaço por ele produzido, ou sob seu marco regulatório, torna-se um instrumento e uma expressão desse mesmo quadro de referência.

Assim, no âmbito da cidade, as decisões do Estado têm implicações diretas no cotidiano das pessoas e, justamente por isso, o espaço urbano carrega consigo toda carga de informações relativas aos seus problemas e às contradições decorrentes da presença ou ausência do poder público. Como exemplo disso, uma das funções do Estado é criar mecanismos que reduzam os obstáculos ao investimento do setor imobiliário no urbano, sem comprometer a existência da propriedade privada do solo (BOTELHO, 2007).

Em relação ao setor imobiliário, o Estado se insere como agente produtor do chão da cidade por meio de obras de drenagem, aterros, abertura de vias de tráfego, gestão da engenharia de tráfego, dentre outros papéis. Essa forma clássica de intervenção no espaço urbano é, predominantemente, realizada em favor do capital, por meio da provisão de infraestru- 
turas urbanas que tendem a gerar rápida valorização do solo, produzindo novas externalidades nas áreas beneficiadas. Na sua ação, o Estado o faz tanto como agente econômico quanto essencialmente um agente político.

Corrêa (2011) afirma que os muitos papéis desempenhados pelo Estado em relação à produção do espaço urbano estão atrelados ao contexto econômico, político e social de cada momento da dinâmica socioespacial. É esse agente que define o marco jurídico de produção e uso desse espaço; impõe taxação sobre aspectos diversos; controla o mercado fundiário, dentre outras atribuições. Assim, o Estado também contribui para a intervenção dos outros agentes produtores do espaço, além de exercer o papel como importante agente econômico, com impacto direto sobre a ação das corporações econômicas e de toda a sociedade.

Sendo assim, a ação do Estado no setor imobiliário caracteriza-se por sua complexidade como condensador de forças e envolve ao mesmo tempo distintos papéis. Com base nos instrumentos de política urbana, tal ação abarca a regulamentação do uso do solo e do espaço público. Em muitos casos, o ordenamento urbanístico orienta os investimentos públicos para beneficiar determinados fragmentos do espaço em detrimento de outros, nem sempre tomando por base as reais carências e necessidades da população, mas, muito mais, os interesses do capital.

Nesse processo, dois elementos sistêmicos, conforme as palavras de Harvey, são os principais responsáveis por estabelecer parte expressiva das contradições que se manifestam na produção do espaço construído. Ou seja:

Por mais que muitos agentes atuem na produção e reprodução da geografia da segunda natureza que nos cerca, os dois principais agentes sistêmicos no nosso tempo são o Estado e o capital. A paisagem geográfica da acumulação do capital está em perpétua evolução, em grande parte sob o impulso das necessidades especulativas de acumulação adicional (incluindo a especulação sobre terra) e, só secundariamente, tomando em conta as necessidades das pessoas. (HARVEY, 2011, p. 152).
Desse modo, o espaço constitui um instrumental para as ações do Estado e é permeado pelas contradições que marcam sua atuação sob o capitalismo. Não por acaso, a relação Estado-espaço revela-se por meio de políticas públicas que visam à qualificação de determinados fragmentos do espaço urbano, orientando investimentos em alguns recortes da cidade em detrimento de outros; as benfeitorias nem sempre se destinam às áreas mais carentes, pois o poder de pressão das frações do capital mostra-se forte o suficiente para direcionar a intervenção do Estado para as localizações que mais lhe interessam.

Diante disso, o Estado é pensado como parte constitutiva da sociedade, cujas contradições decorrem não de um processo interno a ele, mas da luta de classes que se manifestam no conjunto da estrutura social. No ponto de vista do espaço, em última análise, o Estado capitalista põe-se como agente fundamental da contradição de a produção espacial constituir um processo coletivo, mas sua apropriação ser fundada na propriedade privada.

Da mesma forma que o trabalhador, mediante o trabalho, cria o capital como instrumento de sua própria dominação, os seres humanos criam, na forma do Estado, um instrumento para sua própria dominação [...]. Esses diversos instrumentos de dominação - em particular, a lei, o poder de tributação e o poder de coação-podem ser transformados, pela luta política, em instrumentos para dominação de classe. (HARVEY, 2005, p. 80).

O Estado capitalista então se funda na contradição entre os interesses particulares e coletivos, ainda que, até certo ponto e no plano da aparência, assuma uma existência "independente" sob o argumento de garantir o bem comum. Essa contradição converte-se, segundo o autor citado, em outra contradição adicional: a classe dirigente, ao mesmo tempo em que exerce o poder segundo os próprios interesses, afirma e tenta justificar suas ações e estratégias à frente do Estado com a alegação de que estaria a serviço dos interesses da coletividade.

A suposta autonomia do Estado diante dos agentes capitalistas produtores do espaço é apenas aparente, por isso não se contrapõe a eles. Há vários 
mecanismos utilizados pelo capital para pressionar o poder público em seu favor, envolvendo desde benesses até ameaças veladas a agentes públicos. O poder público poucas vezes resiste ao "galanteio amoroso" do capital e age em seu favor, com vista a restringir ou a liberar determinados usos de acordo com os interesses em jogo.

\section{CONSIDERAÇÕES FINAIS}

Como visto, por meio da atuação estratégica dos city builders, o espaço torna-se cada vez mais uma mercadoria bastante valorizada e participa decisivamente do processo de acumulação urbana. Nesses termos, o complexo Reserva do Paiva configura-se como novo referencial de periferia de amenidades no contexto da RMR, ao mesmo tempo em que sua implantação foge à lógica da demolição para a construção, tal como ocorre nos espaços mais densamente edificados da RMR. Constata-se que a implantação desse empreendimento acentua a contradição fundante de sua realização enquanto processo coletivo, mas cuja apropriação é essencialmente regida pela lógica da propriedade privada e com o propósito precípuo da acumulação.

É verdadeiro afirmar que evocar o exclusivismo socioespacial como estratégia para a acumulação urbana é parte intrínseca do jogo dos agentes capitalistas produtores do espaço. Assim, a condição de exclusivo amplamente lastreada pelos city builders em relação aos complexos imobiliários de alto padrão construtivo coloca-se como pedra de toque do processo de acumulação urbana. Por tal lógica, empacotados em um sem número de promessas, os imóveis do complexo Reserva do Paiva se inscrevem no típico jogo da supremacia do valor de troca sobre o valor de uso, mesmo na perspectiva relacional aqui discutida.

Nesse sentido, conforme analisado, o Estado se comporta como forte aliado do capital e procura, na medida do possível, atender às pressões advindas desses agentes. Se hoje alguém perguntasse quem efetivamente manda ou decide sobre o futuro da cidade do Recife e sua área metropolitana, não haveria dificuldade em responder sobre o protagonismo dos agentes privados, mas isso sem deixar de mencionar o papel proeminente do poder público no processo de regulação e de legitimação das iniciativas de proprietários fundiários, incorporadores, construtores, dentre outros que igual- mente interferem na produção do espaço da cidade e logram os frutos financeiros da acumulação urbana.

No caso da Reserva do Paiva constata-se o surgimento de novos interstícios urbano-metropolitanos, à custa da privatização de espaços públicos de acesso à praia, por exemplo, ou até mesmo na apropriação sob a égide da parceria público-privada de reservas florestais e manguezais. Esses elementos de ordem natural passam a integrar a mercadoria imobiliária através da estética anunciada na publicidade.

Em nome do caráter paradisíaco os agentes produtores públicos e privados garantem o exclusivismo socioespacial, e, frequentemente, há a acumulação produtiva da fruição e incorporação dos elementos naturais cuja manutenção e fiscalização para integridade foram caprichosamente asseguradas na lógica de cada jogada estratégica adotada no xadrez do espaço urbano.

\section{REFERÊNCIAS}

AZEVEDO, S. Política de habitação popular e subdesenvolvimento: dilemas, desafios e perspectivas. In: DINIZ, E. (Org.). Políticas públicas para áreas urbanas: dilemas e alternativas. Rio de Janeiro: Zahar, 1982. p. 67-114.

BOTELHO, A. O urbano em fragmentos: a produção do espaço e da moradia pelas práticas imobiliárias. São Paulo: Annablume; Fapesp, 2007.

BRASIL. Lei n. ${ }^{\circ}$ 4.591, de 16 de dezembro de 1964. Dispõe sobre o condomínio em edificações e as incorporações imobiliárias. Diário Oficial [da] República Federativa do Brasil, Poder Executivo, Brasília, DF, 21 dez. 1964. Retificado em 1. ${ }^{\circ}$ jan. 1965.

BRASIL. Lei n. ${ }^{\circ}$ 6.766, de 19 de dezembro de 1979. Dispõe sobre o parcelamento do solo urbano e dá outras providências. Diário Oficial [da] República Federativa do Brasil, Poder Executivo, Brasília, DF, 20 dez. 1979.

CARLOS, A. F. A. A condição espacial. São Paulo: Contexto, 2011.

CORRÊA, R. L. O espaço urbano. 3. ed. São Paulo: Ática, 1995. 
CORRÊA, R. L. Sobre agentes sociais, escala e produção do espaço: um texto para discussão. In: CARLOS, A. F. A. et al. (Org.). A produção do espaço urbano: agentes e processos, escalas e desafios. São Paulo: Contexto, 2011. p. 41-51.

FIGUEIREDO, I. Direito imobiliário. São Paulo: Atlas, 2010.

FIX, M. São Paulo cidade global: fundamentos financeiros de uma miragem. São Paulo: Boitempo, 2007.

GOMES, E. T. A.; ALBUQUERQUE, M. Z. A. A Via Mangue no processo de produção do espaço da cidade do Recife. In: ENCONTRO DA ASSOCIAÇÃO NACIONAL DE PÓS-GRADUAÇÃO E PESQUISA EM GEOGRAFIA, 10, 2013, Campinas, SP. Anais... 2013. Campinas, SP: Unicamp, 2013.

GOTTDIENER, M. O setor imobiliário e o planejamento urbano: controle, gestão e desregulação. In: NERY JÚNIOR, J. M.; SOMECKH, N.; ROLNIK, R. (Org.). Politicas públicas para o solo urbano: experiências e possibilidades. São Paulo: Polis, 1996. p. 17- 26. (Publicações Polis, n. 27).

GOTTDIENER, M. A produção social do espaço urbano. 2. ed. São Paulo: Ed. da USP, 2010.

HABERMAS, Jürgen. The theory of communicative action: Reason and the rationalizalion of society. Boston: Beacon Press, 1984. v. 1.

HARVEY, D. A justiça social e a cidade. Tradução de Armando Corrêa da Silva. São Paulo: Hucitec, 1980.

HARVEY, D. Condição pós-moderna. Tradução de Adail Ubirajara Sobral e Maria Stela Gonçalves. 5. ed. São Paulo: Loyola, 1992.

HARVEY, D. A produção capitalista do espaço. Tradução de Carlos Szlak. São Paulo: Annablume, 2005.

HARVEY, D. O enigma do capital e as crises do capitalismo. Tradução de João Alexandre Peschanski. São Paulo: Boitempo, 2011.
HAUG, W. F. Crítica da estética da mercadoria. Tradução de Erlom José Paschoal. São Paulo: Editora da Unesp, 1997.

LEFEBVRE, H. The production of space. Tradução de Donald Nicholson-Smith. Oxford: Blackwell Publishing, 2007.

LEFEBVRE, H. Espaço e política. Tradução de Margarida Maria Andrade e Sérgio Martins. Belo Horizonte: Ed. da UFMG, 2008.

LEITÃO, G. A construção do eldorado urbano: o plano piloto da Barra da Tijuca e Baixada de Jacarepaguá 1970/1988. Niterói, RJ: Eduff, 1999.

LOGAN, J. R.; MOLOTCH, H. L. Urban fortunes. Berkeley, Los Angeles, Londres: University of California Press, 2007.

MARX, K. O capital. Livro 1. Tradução de Edgard Malagodi. São Paulo: Nova Cultural, 2000. v. 1. (Coleção Os Pensadores).

MARX, K.; ENGELS, F. A ideologia alemã. Tradução de Tamás Szmerecsányi. 11. ed. São Paulo: Hucitec, 1999.

MÉSZÁROS, I. Para além do capital: rumo a uma teoria da transição. Tradução de Paulo César Castanheira e Sérgio Lessa. São Paulo; Campinas, SP: Boitempo; Ed. da Unicamp, 2002.

POULANTZAS, N. O Estado, o poder e o socialismo. Tradução de Rita Lima. Rio de Janeiro: Graal, 1980.

RIBEIRO, L. C. Q. Dos cortiços aos condomínios fechados: as formas de produção da moradia na cidade do Rio de Janeiro. Rio de Janeiro: Civilização Brasileira; IPPUR/FASE, 1997.

SILVA, C. A. F. Segregação residencial carioca sob a égide do capital incorporador. Revista Brasileira de Geografia, v. 57, n. 2, p. 5-27, abr./jun. 1995. 
SMOLKA, M. O. O capital incorporador e seus movimentos de valorização. Cadernos PUR/UFRJ, Rio de Janeiro, ano 2, n. 1, jan./abr, 1987. Disponível em: $<$ http://www.ippur.ufrj.br/index.php?option=com_co ntent\&view $=$ article\&id $=544 \&$ Itemid $=2>$ Acesso $\mathrm{em}$ : 19 fev. 2015.

TOPALOV, C. La urbanización capitalista: algunos elementos para su análisis. México: Edicol, 1979. 